\title{
HISPANIDAD EN TORNO A LA CONQUISTA DE MÉXICO
}

\author{
Rosario Aguayo \\ Colegio Santa Rosalía. Málaga. España.
}

\section{ANÁLISIS PRELIMINAR}

La colonización y conquista de México, como la del Nuevo Mundo, constituyó un factor de importancia en el desenvolvimiento y comunicación de los pueblos autóctonos con los colonizadores, aunque en este proceso, el grado de inmadurez, arrostrara también un grado de destrucción, como acontece a todo acto de esta naturaleza.

No cabe discutir aquí si constituyó un acierto o no, el que España se lanzara a viajar por ultramar, hasta llegar a tierras de América, pues nos guste o no; lo entendamos o no lo entendamos, el hecho sucedió y hubiera sucedido probablemente a pesar de España.

No podemos olvidar que durante parte del siglo anterior, (en 1415, los portugueses llegan a Ceuta y en 1432, don Enrique el Navegante, recorre las costas del continente Africano), la corte de Portugal va a favorecer las expediciones marítimas, cuyo objetivo primordial será el comercio y la adquisión de metales nobles (oro y plata) o piedras preciosas.

Tampoco nos son ajenos otros factores como la consolidación de los diversos poderes o monarquías en Europa; su tendencia al imperialismo... siendo que la mayor parte de los países del contiente, Estados ya (Francia, Inglaterra, Países Bajos), y en alguna medida, Alemania e Italia (si bien su configuración estatal se produciría más tarde, la territorial y cultural estaba y tenía asentadas las bases), así como otros de potencial ya definido, como los Países Nórdicos, Rusia, y en general todos... estaban ya presentes y práctica- 
mente configurados, lo que ponía de manifiesto que poco podían hacer entre sí para extenderse o formar un imperio, en tanto los pueblos indígenas, ya descubiertos, sí podían permitir esta intención. En la mayor parte de los reyes europeos, alentaba la mentalidad de la territorialidad como exponente de poder. Si Europa se hallaba ya parcelada y dividida, era fácil presuponer que la capacidad de extensión habría de dirigirse a otras tierras, que a su vez estaban dotadas de grandes recursos y defendidas precariamente, por lo que de vulnerables (por inferiores, así se les consideró) tenían aquellos que las habitaban.

Cabe pensar, que tal evento, correspondió a España, no por casualidad, evidentemente, pues si potencialmente y culturalmente, cualquier país europeo era apto para hacerlo, sólo España, constituía una Nación organizada y moderna, con poder y economía suficiente, como para interesarse por una hazaña así. Expulsados los moros y judíos, unificada al fín, los conflictos interiores se hallaban a escala menor que los de otros países europeos, que aún pugnaban por lograr su afianzamiento. Su monarquía dotada de poder absoluto y legítimo, se había impuesto por encima de otras sociedades europeas, que andaban embutidas en divisiones anacrónicas y conflictos feudales.

Esto unido a los nuevos avances técnicos descubiertos en las artes marineras u oceanográficas(mayor perfección en la construcción de navíos, en la que los portugueses eran grandes expertos, utilización de aparatos como brújula, sextante, cartas oceanográficas, libros publicados...), conjunta a una mayor divulgación del saber, como mayor necesidad de divulgarlo, así como la difusión de las ideas renacentistas (humanísmo, movimientos reformadores y antireformístas, pero religiosos, afán de riqueza, aventuras y mujeres; no en vano se buscaba el mítico reino del preste Juan, la fuente de la eterna juventud y el reino de las Amazonas), hizo que creciera hasta tomar cuerpo, aquella mentalidad conquistadora-aventurera que propició estos descubrimientos.

Por tanto, no parece descabellado considerar que Europa, y en ella España, se hallaron en estos momentos con el grado de madurez suficiente, como para desarrollar sus ideas imperialistas por ultramar. Este concepto, vivo todavía en la mentalidad europea desde los tiempos romanos, no se desechó ni siquiera en siglos posteriores (lo intentaron en el mapa europeo, sin conseguirlo, Carlos V, Napoleón, Hitler y Stalin, y por ultramar también lo ejercieron Francia, Portugal e Inglaterra).

En el panorama mundial hoy, nos parece impensable (por tan asentados y aceptados .los territorios-Estados), que alguien se atreviese a descomponerlos, por mero afán de conquista, siendo otros, y no los territorios, los 
esquemas que hoy sí tratarían de conquistarse; me refiero al ideológico o cultural, y desde luego, el económico.

Por esta razón podríamos considerar que la historia la crean los hombres, según el grado de desenvolvimiento que mantienen en ella, como de las circunstancias que les acometen. Y fue aquella época, la idónea, para que en ella se diesen los hechos que estamos rememorando. En síntesis, los que siguen:

- Afán de extender el poder, con el consiguiente acrecimiento de la territorialidad.

- Afán de riquezas (tanto a escala individual como nacional) y comercio (factor económico).

- Factores culturales (curiosidad por descubrir; se ignoraban muchos lugares, lo que excitaba la imaginación; necesidad de efectuar intercambios culturales, así como puesta en marcha y comprobación de mecanísmos inventados).

- Factores religiosos (a menudo esgrimidos de forma más coincidente y oportunista que real, por la mayoría de los aventureros, aunque posteriormente, la iglesia cumpliera un papel importantísimo en ello).

A cerca de lo que significó la conquista y colonización de nuevos pueblos, conviene entender, que la mayoría de los analistas, miran estos sucesos desde la perspectiva actual (S. XX) y no, desde la imperante en la época (entre otras cosas, porque no la tenemos), con lo que en ocasiones, los hechos suelen sacarse de su contexto y corren el riesgo de quedar desproporcionados, deformados y tal vez por ello, incomprendidos. Ello los hace vulnerables a la crítica, pues la que hoy nos asiste, se compone de otra mentalidad (tolerante y demócrata) siendo por supuesto, en su mayor parte, anticolonialista. (Voz, que no estoy segura, sea tan determinante como parece afirmar). Bastarían algunos ejemplos de sucesos actuales, para evidenciar que este rasgo de la capacidad del hombre, no sólo no ha sido superado, sino ni siquiera disminuído, aunque nos asista de un modo puntual o concreto y nunca extensivo, como entonces. La guerra surge del afán de conquista y ésta se obtiene a menudo, mediante aquélla...Véanse: guerra civil de Yugoeslavia; Conflicto inglés en las islas Malvinas; invasión rusa en Afganistán; enfrentamientos territoriales entre Ecuador y Perú.... éstos en lo que se refiere a un plano político-territorial, pero el afán de conquista hoy, no sólo hace referencia a este plano. Conquista es también un término incruento, pero no menos bélico, cuando se ejerce a la pasiva, o sin revolución. Ghandi, la realizó frente a Inglaterra, Cataluña la realiza frente a España, vía idioma, las repúblicas Bálticas, frente al sometimiento ruso, Alemania, mediante su unificación, etc. 
Ello se resume en una necesidad del hombre, que trata de medir sus fuerzas, como su potencial y es competitivo por naturaleza, asl, rechaza el plano de la mera igualdad. Existe una necesidad infame de seducción del otro, o de imposición para tornarle vulnerable, o en definitiva débil con respecto a él.

No obstante, existen conquistas gloriosas, que no sólo sirven de modelo, sino que han dotado de identidad a los pueblos sometidos. Raramente los latinos nos dolemos de haber padecido en la antigüedad el acoso de Roma. Esta falta de censura se aprecia por el hecho de que tal conquista supo dar a Europa un plano de asentamiento, de cultura e historia, sin el que hoy, difícilmente seríamos como somos. Pero... ¿era la colonización romana, mejor que las otras habidas? ¿Se conformaban ellos, con menos que otros conquistadores? Creo que humanamente, no. La idea que subyace en la palabra conquista (desde el punto de vista del conquistado) es la de pérdida; pero sin embargo, la que entendemos al hablar de la conquista de Roma, es ganancia. Los pueblos conquistados por Roma obtuvieron civilización. El cambio fue beneficioso. Hubo una composición simbiótica, en donde Roma, se conformó con lo que quería: pueblos y territorios, y éstos a cambio consiguieron: el derecho de pertenecer a la élite del momento (ser ciudadanos de Roma, era un honor verdadero), el derecho a convivir y disfrutar de una cultura, que los construía, sobre lo poseído (los romanos fueron respetuosos con las costumbres de los pueblos sometidos).

No sé si una razón del anticolonialismo, entre otras muchas de carácter ideológico, que impera en este siglo (no así en otros anteriores) sea debi$\mathrm{da}$ a que en las colonizaciones posteriores al medievo, no se ejerció (no se supo o no se pudo) una condonación de papeles auténticamente válida, y quedara cada civilización más desprotegida, desfavorecida o aislada, que antes de efectuarse el proceso. Algo para entendernos, como "desnudar a un santo, para vestir a otro". No olvidemos, que el proceso colonizador de Roma, duró 1500 años, si bien durante los primeros siglos, se ejerció propiamente el de la conquista, en los posteriores se consumó la romanización, o conquista espiritual, auténtica valedera de éxito.

Según este esquema, ni la colonización de España, ni otras colonizaciones ejercidas con posterioridad, por otros paises, durante los siglos XVI al XIX, lo fueron tan profundamente como la romana, y el proceso iniciado quedó inconcluso, mucho antes de ser asimilado por completo, debido a una agilidad de cambios o esquemas de progreso en el tiempo (conocimientos, avances técnicos, sistemas tecnológicos y políticos), que impiden y de hecho han impedido, el necesario asentamiento. Fueron meras conquistas territoriales, que no reemplazaron en profundidad la base sustentadora de esos pue- 
blos, dotándoles de identidad consecuente. En el caso de España, con América latina, la única la aporta el lenguaje, vínculo de naturaleza superior, pero no la tradición, que llega a ser en ocasiones, muy importante. Es ahora, cuando incluso la tradición, comienza a ser española, pero no así, al principio; de ahí que en la actualidad, el principio de españolización, se halle mucho más vivo que en siglos más inmediatos a la conquista. Según don Manuel Alvar, de la Real Academia de la Lengua Española, mil veces se ha dicho: "América es una utopía que está por realizar. Pero utopía la hubo en el momento en que soñaron los clérigos y los legisladores, o en el pensamiento de Bolívar, o en las Constituciones de los pueblos libres de América. En los nuestros se independizaron los esclavos mucho antes que en los EE.UU. y Brasil, se consideró hombre libre al esclavo que pisaba la república recién constituida, utopía fue que todos los hombres son iguales, y que con una instrucción elemental, se lograba la libertad de espíritu. Vinieron los fueros de la realidad y ensombrecieron los sueños, pero la luz había sido entrevista, y en muchos casos, dura. Y la libertad acabaría aunándose en la lengua. Otra utopía, acaso la única, que cobrará plenitud".

Para Alfonso Reyes, podría en vigor prescindirse de algunos orbes culturales de Europa, que no han hecho más que prolongar las grandes líneas de la sensibilidad o del pensamiento. De lo ibérico no podría prescindirse, sin una espantosa mutilación. De suerte que lo ibérico, tiene en sí un valor universal. Y a éso, añadirá Amado Alonso, que de esos valores que en nada amenguaron a lo que de válido hubo en el período indígena, surge el valor de la entrega, pues la diferencia de la colonización española se basa en un pueblo, que se desborda en "energla personal", ante la que las nociones de religión, de monarquía y libertad, se vinculan a la creación del pueblo desconocido, que se llama lisa y llanamente "Juan Español". Así surgieron las naciones de América... Es la herencia recibida y fuertemente consolidada, porque ni en los días más amargos del hundimiento de España, aquel mundo se vino abajo, sino que mantuvo su capacidad creadora.

"Resulta entonces, que la Lengua, se funde en una metafísica o representación del mundo. Es lo que los idealistas han sustentado y lo que Alfonso Reyes, vino a aprender desde el hogar científico, que fue el Centro de Estudios Históricos: la Lengua como reflejo de cultura, que es tanto como decir senda para la integración, testimonio de hermanamiento y unidad espiritual". (Manuel Alvar)

Añadirá así mismo, don Manuel Alvar, que los estudios más recientes dicen que unos tres millones de almas sólo, hablarían español, en la independencia, en el continente. La difusión mayor de nuestra lengua tuvo lugar con posterioridad a 1810. La Constitución de Bolivia dice que "La Lengua 
es el recurso para unir los miembros dispersos de las comunidades nacionales" o "para crear naciones nuevas" — dirá Panamá.

En su Tratado Conciencia Social y Deber Social, Alfonso Reyes, dirá que es el instrumento de concordia de todos los pueblos de América. Y aún añadirá en su Discurso por la Lengua: "Sólo declaro al comenzar, que considero un privilegio hablar español y extender el mundo en español".

Los pueblos colonizados en lo que pudiéramos considerar, modernidad, lo son a medias. Han empapado grandes aspectos y asimilado mucho de la potencia conquistadora, pero no han modificado su identidad del todo. No lo hicieron en un principio, aunque modificaron mucho por vía de la imposición, y no lo harían ahora de buen grado, pues la propia ideología de autoafirmación del siglo, también incide sobre ellos. De ahí que surjan facciones contrapuestas, las unas aspirantes a reivindicar los ancestros y las otras, a afirmar y asegurar lo aprendido. Estos países se tornan híbridos, la cultura no se acepta como una, no se estratifica con el nivel de conveniencia en el tiempo, hasta aglutinar lo pasado y lo moderno en un todo sino que fluye en planos divergentes, que tratan de chocar y confrontar entre sí, lo que les divide, les ocasiona problemas y disensiones propias de todo ente no configurado ni asentado por propia aceptación voluntaria. (La crítica ejercida con respecto a la dominación hispana, que ha negado a España el recurso de padrinaje desinteresado, igualándolo -y no es lo mismo- al papel ejercido por otros países conquistadores de mayor poder depredador, de actos mucho más crueles e irrespetuosos, como pudieron ser Inglaterra o Francia, ha servido para crear o sembrar la división, entre los nativos, con respecto al papel hispano).

Es obvio que la romanización fue un proceso de síntexis lento y por ello, absorbido. No hubo cambios sustanciales en la manera del vivir del hombre durante 1500 años, y en cambio, sí se han producido desde el S. XVI al XX, particularmente en este último. A partir del S. XVII, estos cambios han sido contínuos aumentando en número como en nivel y condicionando cada vez más la gestión de las sociedades en sí y su interacción con las otras sociedades. Las costumbres del ser humano, desbordado por la técnica, han tenido que modificarse, exigiendo de él una adaptación contínua. Esto ha conducido a los países hacia otros modelos y parámetros divergentes con los tradicionales, que les han hecho diverger entre sí, según el grado de avance de cada país. Paralelamente, el progreso técnico ha llevado aparejado el desarrollo económico, lo que ha multiplicado las distancias entre unos países y otros, así como su potencialidad. Sin olvidar, el plano ideológico y político, que ha establecido barreras en la identidad de los pueblos y en su afirmación (antiguamente el modo de gobernarse era similar en todos los países, y aun- 
que fuera diferente, no comportaba los mismos riesgos que las divergencias políticas en la modernidad). En la actualidad, tanto los esquemas políticos, como económicos y científicos han acentuado tan gravemente las diferencias, que existe un eje Norte-Sur, en torno al cual se aglutinan los países considerados ricos, y los pobres, con las consiguientes mermas culturales y de desarrollo entre ambos.

América latina, ha sido y es, una de las facciones atrapadas en el inmovilismo de una inadecuada estructura económica, cuyas razones son complejas de definir. Es posible, que España, haya mantenido en este campo una desasistencia funcional, que haya podido agravar más este subdesarrollo, lejos de mantener un apoyo base más uniforme y sostenido, debido a sus propias crisis internas... Parece desde luego existir una descorrelación entre el soporte técnico-tecnológico y económico, que contradice el grado de acercamiento cultural y linguístico, en proporción inversa a la colonización en sus primeros momentos.

Para entender lo que significó esta conquista, hay que retroceder al siglo XV o principios del XVI. Conocer a la sociedad existente en aquella etapa en México, ver sus esquemas organizativos y su línea de sustentación con el pasado y especialmente con el futuro. Pero no sólamente conviene saber lo que ellos eran, sino apreciar lo que éramos y representábamos nosotros, y tras ello, en paralelo, trazar un símil de confrontación política, económica, social y religiosa como el que se añade:

Procedamos a ver en un principio cómo la sociedad indígena anterior y durante nuestra llegada, era una sociedad jerarquizada entre sí (caciques, príncipes, reyes y nobles) y sus estados (federados). "Imperio poco centralizado, confederación, economía mercantil apoyada por una fuerza militar... El mantenimiento de lo que ya se consideraba un estilo de vida normal, dependía de los miles de cargadores o tamenes que transportaban los tributos de las ciudades dominadas... Si bien, las ciudades importantes tenían que soportar la presencia del recaudador mexicano (calpixque), y aunque en algunas había guarnición, los mexicas evitaban el coste de un imperio centralizado, gracias al sistema tributario, siendo que a condición de enviar los materiales requeridos, las ciudades podían autogobernarse" (Hugh Thomas)

Era una sociedad distribuída en clases y categorías sociales. Existía, como en la mayoría de las sociedades de la época, el dominio del hombre sobre la mujer. Poseía tradiciones y preceptos, así como un grado de religiosidad que consistía en prestar adoración a diversos ídolos de piedra, o dioses, 
de diversa advocación y efectividad (Tlaloc, proporcionaba la lluvia y la fecundidad de los campos; Quetzalcoatl, era así mismo dios de la paz, de la abundancia, y Huitzilopochtli, cuyo nombre significaba "colibrí de la izquierda" o "del sur" era encarnación del sol, siendo suyos la guerra y los enemigos. Como toda sociedad bien constitulda, prestaba obediencia al emperador, máxima jerarquía, o autoridad suma, cargo que recaĺa en aquellos momentos en la persona de Moctezuma II: "Poseía gravedad y entereza en el semblante, que solían decir los indios que le venía bien el nombre de Moctezuma, que en su lengua significa "principe sañudo", aunque procuraba templar esta severidad forzando el agrado con la liberalidad. Acreditábase también de muy observante en el culto de su religión. Tuvo gran altivez, se hizo servir de nobles hasta en los ministerios menos decentes de su casa. Dejábase ver pocas veces de sus vasallos y sólamente lo muy necesario de sus ministros y criados, tomando el retiro y la melancolía como parte de su majestad... Sus audiencias no eran fáciles, ni frecuentes, pero duraban mucho, y se adornaba esta función de grande aparato y solemnidad. Entraba descalzo el pretendiente y hacía tres reverencias sin levantar los ojos de tierra, diciendo en la primera "Señor", en la segunda "Mi Señor" y en la tercera "Gran Señor". (Antonio de Solís)

"...En los años setenta del S. XVI, fray Durán, preguntó a un anciano indio qué aspecto tenfa Moctezuma. El indio respondió, que aunque habla vivido cerca del emperador, no lo sabla, pues nunca se habla atrevido a mirarlo". (H. Thomas)

Era una sociedad culta, como lo demuestran sus libros escritos, en forma de láminas plegadas, con dibujos ideográficos, su forma de hacer el papel: "...Las ofrendas se inscriblan meticulosamente en un papel fabricado con la corteza interior de una higuera silvestre (amatl)". (H. Thomas)

“...Los mejicanos tenían dos clases de papel, uno llamado metl, que se hacía con las pencas del maguei, que nosotros llamamos pita, pudriéndola para sacar, lavar y unir sus fibras por medio de goma: éste le brunían para pintar en él. La otra clase se hacía de las hojas de la palmera, por un método semejante al anterior: era muy blando y blanco, y en la suavidad parecía de seda, porque también le brunían". (A. de Solís).

Poselan tejidos, siendo diestros en el arte de tejer algodón, en forma de paños con rayas, o piezas de hilado muy sutil y fino. Hacían cerámica, construían casas de una planta con azotea, algunas veces, diques, e incluso islas artificiales, en que robaban parte a las aguas del lago, echando piedras, tierra y bejucos, que la retenlan, trabándose entre sí. Realizaban pirámides de porte majestuoso, escalonadas, que hicieron recordar en principio a nuestros conquistadores, las existentes en Egipto, las cuales servían como templos y ara de 
sacrificios, solían adornar estos templos con estatuas, dedicadas a sus dioses, por lo que el arte escultórico, también tuvo lugar en su civilización, siendo grandes expertos en trabajos de orfebrería: “...Era entre todas la ciudad de Tlatelulco de admirable capacidad y concurso, a cuyas ferias acudían ciertos días del año, todos los mercaderes y comerciantes del reino con lo más precioso de sus frutos y manufacturas. Según dice Antonio Herrera, una de las mayores del mundo, se llenaba de tiendas puestas en hileras y tan apretadas, que apenas dejaban calle a los compradores. Había hileras de plateros, donde se vendían joyas y cadenas extraordinarias, diversas hechuras de animales y vasos de oro y plata, labrados con tanto primor, que algunos de ellos dieron que discurrir a nuestros artífices, particularmente unas calderillas de asas movibles, que salían así de la fundición, sin que se conociese el impulso del martillo, ni golpe de cincel". (A. de Solís).

También poseían leyes y ejercían la aplicación de ellas a través de jueces: "...Había casa diputada para los jueces del comercio, en cuyo tribunal se decidían las diferencias de los comerciantes y otros ministros inferiores, que andaban entre la gente, cuidando de la igualdad de los contratos, y llevaban al tribunal las causas de fraude o exceso que necesitaban castigo". (A. de Solís). Eran grandes observadores del espacio y conocían la astronomía y el calendario con bastante fiabilidad: "...Dos calendarios que habían asimilado de civilizaciones anteriores del Valle de México, les proporcionaban continuidad: el tonalpohualli, con un total de doscientos sesenta días divididos en veinte semanas de trece días cada una; cada día indicaba la suerte especial de los que nacían en esa fecha, y cuyo nombre reciblan; y el xiuhpohualli, basado en el año solar de trescientos sesenta días, divididos en 18 meses, los cinco días adicionales del año de trescientos sesenta y cinco días (los mexicas habían comprendido mucho antes que esta era la medición correcta) eran "días valdíos" y "aziagos". Cada 52 años en México empezaba un nuevo siglo. (H. Thomas).

Era en fin, una población con recursos y por tanto con estructura militar, política y económica: mercados, (Tlatelulco) para intercambio de productos de todo tipo, impuestos tributarios, sistema de aduanas, moneda (bayas de cacao), metalurgia, agricultura y caza. Era una sociedad con valores y a tal fin se educaba a los ciudadanos, mediante escuelas de diversos tipos, pues las había esencialmente militares, y otras de primaria, con bastante similitud a las escuelas occidentales, siendo que los maestros compartían un rango similar al de ministro; había especie de conventos para las mujeres mientras estaban solteras, en donde se les enseñaba a tejer o realizar tareas eminentemente femeninas... Posela ejército, distribuído en diversas órdenes o batallones, con distintivos propios para cada una. Así había compañías 
cuyo estandarte y signos eran el águila, el jaguar, el tigre etc. Conocían otras técnicas, equivalentes a las de los pueblos de la época más desarrollados, como era la extracción de sal y minerales, la canalización del agua y sistemas de irrigación en los campos, construcción de calzadas, acueductos, puentes...

En definitiva, nada se echaba a faltar en ella, que la hiciera desmerecer de cualquiera otra sociedad legitimamente establecida. Cualquier sociedad europea, y entre ellas, la española, poseía así mismo todos estos elementos, por los que se autoafirmaban, sin tener que demostrar ante nadie, que eran focos de civilización y por ello, civilizadores.

La categoría de salvajes aplicada a los indios en México, como en otras conquistas posteriores, no indica sino el grado de presunción e ignorancia, con que les acometíamos, situándonos en un estadio de superioridad erróneo. Era cierto que poséamos una superioridad impuesta por los siglos: un sustrato cultural básico, generalizado al orbe blanco, con el que nos identificábamos, si bien, los indios poseían su propio sustrato, no equiparable en cuanto a lo que hoy se denomina sabiduría universal o clásica (la procedente de Grecia y Oriente Medio), la absorbida por Roma y por todos sus pueblos conquistados... Mas no fue esta diferencia, la que supo imponerse, sino otro nivel superior, que nada tiene que ver con la auténtica superioridad humana: el de las armas.

Éramos más diestros en la guerra, y más crueles.Poseíamos ya, numerosos mecanismos y recursos (tácticas) para matar, obteniendo victoria. Los indios ejercían su nivel de intolerancia (crueldad para nosotros) en sus actos religiosos. Eran actos, en efecto, mortales, dañinos, pero no tan crueles como pudo pensarse, toda vez que la creencia religiosa los afectaba de causa y reverencia hacia un dios (por más que falso) y una meta (por más que errónea). Eran actos más propios de la ignorancia, que de la maldad, aunque también la poseyeran como cualquier ser humano, y desviaran propósitos oscuros, hacia la imposición de tal costumbre. Si bien, estos actos dependían del tipo de dios al que se dirigían - de ahí su matiz religioso y no meramente despiadado- pues Quetzalcoatl, venerado en todo el imperio, pero principalmente en Cholula, era un dios de paz y de armonía, que prohibía estos excesos, reprobándolos. Las guerras floridas no tenían el afán de reducir al enemigo para robarle o privarle de su libertad, violentar sus mujeres y destrozarles, arrebatando sus bienes... eran un acto más que Moctezuma hacía confluir con la religión, en las que en vez de obtener un beneficio para sí, lo obtenía para sus dioses, especialmente para favorecer el culto de "Huchilobos" (así llamaban nuestros conquistadores a Huitzilopochtli), ya que con ellas se permitía capturar prisioneros para los sacrificios: 
“...En los festivales habían ofrendas: animales o aves, sobre todo codornices, y cada vez con más frecuencia, seres humanos, generalmente prisioneros de guerra o esclavos, comprados especialmente para este propósito... Presumiblemente antes de independizarse de los tepanecas en 1428, los mexicas practicaban el sacrificio humano a una escala modesta, a fin de complacer a sus dioses... Más a partir de 1430 , cuando los mexicas empezaron a construir su imperio, los sacrificios humanos se hicieron más frecuentes. Los mexicas habían llegado a dar importancia a una extraña estratagema: las guerras floridas. Las batallas constituían una buena propaganda y obtenían prisioneros para las piedras de los sacrificios" - dirá Hugh Thomas.

Este beneficio era compartido, pues el pueblo contrincante también podía proveerse de prisioneros enemigos, sin daniar a sus paisanos con sus prácticas religiosas. No obstante las exigencias de esta costumbre abominable, les llevaba incluso a sacrificar a los propios (niños o jóvenes, a los que preparaban durante todo un año, como si fueran la reencarnación del dios) sin considerar la maldad de tal acto. (Costumbres terribles hemos visto en todos los pueblos incultos o ajenos al saber occidental). Puede ser éste el motivo por el que los españoles les llamaron salvajes. Hoy, casi podemos pensar que había más salvajismo en el modo de violentar sus tradiciones, sus usos, o de hacerles la guerra (cañones, culebrinas, ballestas, arcabuces, caballos...) de los españoles, pues ellos nos atacaban con espadas de obsidiana (que herían sin cortar, ni matar, por lo gruesas y quebradizas); sus lanzas eran de palo, con puntas de hueso afilado, fácilmente reducibles, solían esperar a la luz del día para atacar (no gustaban luchar de noche) y se disponían linealmente en llano, en vez de buscar lo quebrado o lo tortuoso del terreno, como hacíamos nosotros.

"...De la victoria de Potonchan Cortés sacó varias lecciones. En primer lugar se dió cuenta del gran impacto de la artillería. En segundo lugar, los castellanos vieron que en una batalla librada entre ellos y un número aplastante de indios, podían salir victoriosos sin grandes pérdidas. Una tercera lección probablemente fuera que para protegerse de las espadas afiladas, pero quebradizas de ese enemigo, se precisaba únicamente una armadura de algodón, como las que Cortés habla visto en Cuba (escaupiles, en voz castellanizada de los soldados. Sólo emplearon a partir de entonces las de metal por su efecto intimidatorio y psicológico). La impresión producida por Cortés y una docena de jinetes fue espectacular. Los indios creyeron que eran monstruos. Uno de los jinetes, que más se distinguió, fue Francisco de Morla, montando un caballo tordo: puso a los indios en gran aprieto, quienes creyeron, al parecer, que se trataba de un centauro. La victoria de un puñado de jinetes sobre un gran número de indios no se debió únicamente a los caballos y los hombres 
que los montaban, sino también, como siempre, a las tácticas de los indios, cuya tradición consistía en atacar de frente. Por consiguiente sólo la primera fila podía luchar; cuando ésta era derrotada, seguía la segunda y luego la tercera... La artillería era importante en este aspecto, pues matar a distancia significaba la deshonra para los indígenas, delicadeza que no afectaba a los castellanos, a quienes les era indiferente el modo de matar al enemigo: lo importante era matarlo." (H. Thomas)

"...Las bocas de fuego peleaban con el daño que hacían y con el espanto que ocasionaban: la artillería lograba todos sus tiros... Y como era uno de sus primores (de los tlaxcaltecas y demás indios) el esconder los heridos y retirar los muertos, a fin de que el enemigo no conociera sus pérdidas, se ocupaba en esto mucha gente y se iban disminuyendo sus tropas." (A. De Solís).

Nos recibieron amistosamente, señal de su falta de desconfianza: "Juan de Grijalva, después de asegurarlos con algunas dádivas, les razonó por medio de sus intérpretes que él y todos quellos soldados eran vasallos de un poderoso monarca, en cuyo nombre le ofrecían la paz y grandes felicidades, si se reducían a su obediencia. Lo oyeron con atención desabrida y uno de aquellos bárbaros, respondió a Grijalva con entereza: "que no le parecía buen género de paz la que se quería introducir envuelta en la sujeción y en el vasallaje, ni se podía dejar de extrañar como cosa intempestiva, el hablarles de un nuevo señor, hasta saber si estaban descontentos con el que tenían; pero que en el punto de la paz o la guerra, pues allí no habla otro en qué discurrir, hablarían con sus mayores y volverían con la respuesta". Volvieron los mismos indios con señales de paz, diciendo: "que sus caciques la admitían, no porque temiesen la guerra, ni porque fuesen tan fáciles de vencer como los de Yucatán (de lo que ya tenían noticias) sino porque dejando los nuestros en su arbitrio la paz o la guerra, se hallaban obligados a elegir lo mejor". $Y$ en señas de la nueva amistad que venían a establecer, trajeron un regalo abundante en bastimentos y frutos de la tierra. Llegó poco después el cacique principal con moderado acompanamiento de gente desarmada, dando a entender la confianza que hacía de sus huéspedes, y que venía seguro en su propia sinceridad... Después de los cumplimientos mandó que llegasen sus criados con otro presente que traían diversas alhajas de mayor artificio, plumajes de varios colores, ropas sutiles de algodón y algunas figuras de animales hechas de oro sencillo..." (A. de Solís)

Todo esto nos lleva a considerar que su grado de barbarie no era tan alto, como tampoco lo era nuestro grado de humanidad. Pues nosotros siempre supimos a lo que íbamos; lo hicimos a cualquier precio, utilizamos los recursos de nuestra sabiduría o progreso, para hacer el mal, porque en ello estaba la victoria, conscientes y decididos a emprender aquella trayectoria, 
que en nosotros era "ofensa" y en ellos "defensa". Nuestra psicología utilizó los más sutiles ardides y trampas. Estrategias que aseguraban la dominación.

Podemos decir no obstante como en el caso del alumbramiento, que es necesario el parto, para obtener el placer de vivir. A veces de una enfermedad se obtiene un fortalecimiento, y en este caso, España, como primero Roma, tuvo que imponer sus sistemas (terribles a los indios) para después pacificar, educar, acostumbrar o colonizar, que fue lo que se hizo, con mayor o menor acierto.

Conformémonos pensando que ninguna apropiación territorial se hizo de modo voluntario y completamente incruento, en la época de que hablo, y por ello, mejor será centrar sus consecuencias, mejores de lo que pudieron pensarse en principio y peores de lo que querríamos que fueran, en la actualidad.

En el contexto de lo que supuso el descubrimiento de América, Hernán Cortés significó lo que el Cid en la reconquista española (posiblemente, en parte se inspirara en él); pese a su superioridad psicológica, no la ejerció en modo humillante, ni cruel, si bien no eximió sus actos de la firmeza necesaria. Fue un investigador, aventurero, dinamizador, que ejerció auténtico liderazgo y poseyó carisma para imponerse a sus hombres, divididos y en parte, debilitados por las acusaciones de Diego Velázquez (rebeldes) y su posterior persecución, que no dejó de asistirles en todo el trayecto. Pocos jefes sobreviven y ganan la sumisión de sus hombres (por demás ignorantes, asustadizos, dados a cambiar de héroe a cada momento; tampoco hay que ignorar que tuvieron el mejor: el oro y las riquezas prometidas, promesa que Cortés debió ponderar en los peores momentos y con la que supo dirigirles y animarles), pero aún a pesar de ello, grande tuvo que ser su perspicacia, su sabiduría o su sentido práctico (menos libresco, pero más efectivo a la hora de tratar con quien tuvo que hacerlo: la soldadesca y los indios) y aún grande, su suerte o su oportunismo en el tiempo, y en las circunstancias que le asistieron, que confluyeron en él, y de las que supo aprovecharse, pues poseyó intérpretes magníficos, lo que mejoró sensiblemente las condiciones de la aventura, y llegó en el momento en que el pueblo mexica, y con él su emperador, consideraba era llegado el fin de los tiempos conocidos, y el propio Moctezuma lo recibió como reencarnación del dios Quetzalcóatl, que había de volver de oriente.

Muchos son los momentos claves e importantes de esta conquista, pero sin duda hay varios tan determinantes, que le auguraron el éxito, por mor del riesgo y la genialidad, lo que otroga a Cortés la categoría indiscutible de mito. Veamos: 
- En principio la rebeldía de que Diego Velázquez le acusa, va a determinar que entre sus hombres y él se estreche el vínculo de "prófugos", lo que servirá para unirles, por más que haya ocasiones en que les mine y debilite, enfrentándolos.

- Tuvo el valor de deshacerse de los barcos (audacia o genialidad, que hubiera podido costarles la vida), pero con la que aseguró la empresa, al evitar a sus hombres el pánico, la huída o el desmoronamiento. Dirá: "Ya no hay sino vencer, o morir".

- Realizó un sometimiento incruento y psicológico del monarca, aprovechando su creencia en el destino, siendo admirado y querido por él (Moctezuma llegó a reconocerse súbdito y vasallo del rey Carlos I)

- Aprovechó su permanencia en Tenochtilhán, para realizar un estudio estratégico de las calzadas, los lagos y puentes, lo que luego le serviría en su definitiva batalla naval, pues fue por mar y no por tierra, que logro sitiar la ciudad, reduciendo a sus moradores por hambre y sed, hasta tenerla vencida.

- Innegable su habilidad para asegurarse confederados a los otros indios, verdadera cuña que debilitó al imperio mexica. No olvidemos que pisó Yucatán con apenas 500 hombres, y sitió Tenochtilhán con más de 200.000. Su conquista es un modelo militar.

Tampoco será fácil quitar a Hernán Cortés la gloria de haber sometido su empresa a una tenacidad ideológica, vertiente en dos principios universales; servir a Dios y al rey. En ningún momento sintió debilidad por la defensa de estos postulados, y con ello, alzó las tierras indias al privilegio de súbditos confederados con la nación de más alto rango, entonces en la historia y elevó con gran empeño el alma indígena hacia los principios de Jesucristo, llevado al conocimiento de aquéllos por primera vez, evangelización veraz, que no sólo trató de apartar de los indios las terribles ceremonias que ofrecían a sus dioses, sino que supo informarles de la verdad, de la fe y abrir por vez primera, la puerta del verdadero y universal humanismo.

Este fue el primer concierto o lazo auténtico establecido entre España y el Nuevo Mundo. La cuerda que ataba el destino de occidente con oriente. La línea de la civilización romanizada, humanista y cristiana.

Es cierto que otros conquistadores, anteriores y posteriores lograron éxitos. Pero es posible considerar que ninguno de ellos, poseyó la sutil inteligencia de este español heróico, que siendo conquistador y ejerciendo la dominación, fue caballero. Que enamoró a Moctezuma, el emperador más respetado, más egregio de todo aquel ámbito, el más poderoso, el cual no sólo se sometió a su diligente actividad, sino que admiró profundamente el saber 
hacer de un hombre, que siendo extraño, resultó cordial y habiendo sido considerado enemigo temible, fue respetuoso, concediendo amistad y recibiéndola del monarca que a todos causaba temor.

No hay mayor conquista que la que sabe ejercer la persuasión y la que es aceptada con admiración inteligente. Si Hernán supo persuadir, no es menos cierto, que Moctezuma, tuvo la talla ingente de saber comprender y aunarse a este intento. y lo que hoy sabemos todos, es que ésta fue la auténtica conquista; voluntaria de tal modo, que en vez de contrarrestar dignidad al monarca, le otorgó la que concede la inteligencia a los seres superiores, capaces de darse cuenta de su papel en cuanto al tiempo. Moctezuma cedió su rango al progreso venido de oriente. Comprendió - posiblemente muy influenciado por sus creencias en el destino profético- que había finalizado una etapa y comenzaba una nueva era. Por éso no opuso ninguna resistencia. ¿Podríamos hoy, resistirnos al avance científico, aunque no nos guste? Nuestro intelecto comprende su veloz impacto, que nos arrebata y modifica implacable las costumbres, mejorando las unas o empeorando las otras (especialemente las tradicionales) Pero... ¿no sería tenido por locura, el intentar frenarlo?

Hoy sabemos bien, cómo en su día el propio Moctezuma supo, que frente a un choque de culturas, cede la más imperfecta tecnológicamente. Era evidente nuestra superioridad, y este rey, de proporciones incalculables, se dejó seducir por ella.

Lo más controvertido no fue en sí este capítulo fácilmente asimilable, sino el posterior y subsiguiente aserto, en el modo de proceder de España. Pero para éso convendría situarse en pleno S.XVI y tratar de comprender los avatares que la propia España sufría. ¿Cómo se hallaba nuestro país durante la conquista? ¿Cuáles fueron sus condiciones posteriores?

Mejor época le ocupó a Cristóbal Colón su descubrimiento, por lo que de firmeza tenían los reyes que le enviaban, y de asentamiento, aunque incipiente, la nación de la que partía. La España de los reyes Católicos, no poseía otra distracción, en esas fechas, que la de extenderse tanto por Europa, como por América. La España de Carlos I, tuvo que dedicarse a conservar y defender el ingente legado territorial y espiritual que sus abuelos le habían dejado. Evidentemente, siempre es menor el riesgo de conquistar o poseer algo no poseído, que el de perder algo que se posee y se quiere seguir poseyendo.

España, disoluta una vez más, como tantas en la historia, tan pronto era de Carlos, como de Juana... El propio Carlos tampoco lo tuvo en claro en principio: disgustó a nobles y paisanos por sus costumbres flamencas, por 
sus amigos extranjeros, a los que nombró ministros, desautorizando los intereses de propios... Se dejó atrapar por la ambición de una mayor conquista en Europa (la corona de Alemania), cuando al otro lado del mar, era dueño de medio mundo; y se enfrascó en estos afanes interesados, como lo hubiera hecho por una novia caprichosa.

La dividida España no sabía a qué atenerse. Tan pronto era de Carlos como de Juana... Los nobles aspiraron a sacar partido de este dislate, que andaba disolviéndola y la mantenía confundida. Los Comuneros se alzaron en armas y Carlos hubo de desbaratar estos intentos, además de enfrentarse a los del rey de Francia, a los flamencos, a los propios príncipes y nobles alemanes, más tarde... ¿Podía el rey, con aquellos aprietos mirar hacia poniente con ojos de conquistador-aventurero? Todavía América era algo lejano, casi intemporal que podía seguir esperando, puesto que tantos siglos habla aguardado a ser descubierta.

Para una nación tan importante como España, en el mundo, tan poderosa, tan católica... no iba a suponer riesgo alguno, demorar aquel lejano objetivo de ultramar, que se iba haciendo a sí mismo (vía aventureros, clérigos, virreyes, encomenderos etc.), que ya estaba presente para el mundo civilizado y al que el papa Alejandro había autorizado para ser español... La España del S. XVI y la del XVII, como la de sucesivos siglos, no pudo olvidarse de sí misma, para entregarse a su homónima de ultramar con mayor ahínco. Bien es verdad que tuvo el acierto de evangelizarla y por ello, los indios se vieron en la ocasión de gozar de conventos y escuelas, antes que verse reducidos a Reservas, tal sucedió a los de América del norte, caídos en poder de políticos y no de hombres con espíritu vocacional. Sin que tampoco ello elimine los muchos excesos que se cometieron, pues si generalmente el hombre, en su modo de ser, cuando se sabe superior, trata al inferior y le somete a pautas extrañas que le humillan, por más que no lo pretendan, ¿qué diremos de aquellos encomenderos, clérigos, virreyes, corregidores, jueces, pesquisidores... que además usaban la prepotencia y la soberbia, de la monumental época y el importante país que les sostenía?

No fue fácil para América deshacerse de sus mitos, para acogerse a foráneos. Mucho trabajaron allí los espanioles que estuvieron. Mucho ayudó la cordialidad indígena, dócil y reverente a los "teules" venidos de oriente. Mucho contribuyó el mestizaje, la fusión de las sangres, porque en ella había aceptación mutua y entrega paralela. y cierto es que España se desentendió, sin olvidarles, y teniéndoles presentes, hubo de asomarse a sí misma, porque rara vez, la paz la coronaba. Muchas guerras externas tuvo que afrontar durante aquellos siglos: Francia, Inglaterra, países Bajos, Holanda, Alemania, y aún Suecia, Dinamarca, tras la paz de Westfalia. Sus sueños europeos se 
vinieron abajo. Incluso estuvo a punto de ser invadida ella misma, por Drake, por Napoleón, Nelson... Todos trataron de debilitarla o apropiársela del todo o en parte. y cuando no los extranjeros, eran los propios: absolutistas, liberales, carlistas, isabelinos... Siempre, siempre, tocada de cicatrices internas y externas. A pesar de ello, al par casi con su propio desenvolvimiento, las primeras universidades se hicieron alli. Alli el hermanamiento, en solidaridad con lo que aquí existla: iglesias, escuelas, audiencias, ayuntamientos, ciudades, universidades... Bien es verdad, que aquél era otro mundo, demasiado grande tal vez, para la "pobre península" (en el decir de Manzoni), y España no supo o no pudo acaparar y aunar el desarrollo de aquellos, al suyo propio. Algo sí les desarrolló al par, en hermandad absoluta e indiscutible: el espíritu. Creó en ellos los mismos afanes y volcó nuestro saber, nuestra cultura, hasta empapar con ella, filtro riquísimo sus raíces.

Sinceramente no puedo dejar de censurar la dejadez habida, después de habernos concedido unos y otros, tanto. Comprendo los múltiples y disonantes problemas de este país al que pertenezco, y admiro, pero insisto en que ha habido momentos en que esta dejadez se ha convertido en lacra, en ingratitud hacia la obra bien hecha.

Si el paralelismo, como la naturalidad del éxodo iba bien en los siglos en que los cambios sociales no establecían graves diferencias y el desentendimiento fue menor, España debía haber extremado sus cuidados, durante las épocas en que empiezan a patentizarse de nuevo las diferencias ( $\mathrm{S}$. XIX y XX) Estas, (grado de progreso técnico y evolución económica) para América, debieron ser "abandono". Factores que contribuirán a que la propia América se nos desenganche, serán entre otros: la insurrección y vocación independentista de los criollos, como la interacción de otras culturas europeas, de mayor empuje económico. No olvidemos que en América del Norte, la cultura anglosajona se ha impuesto, y con ella, los EE.UU. van a adquirir un auge imprevisto, que va a poner en tela de juicio la eficacia de otros colonizadores, cuyos recursos son más infecundos y sus países más pobres. Como un niño desasistido, por la fuerza psicológica de su madre, América se va a cuestionar con amargura (en voz de algunos), las ventajas de haber pertenecido a España... (una España enfrentada en luchas internas parte de los siglos XVIII, XIX y XX)

Sin embargo, un factor de factores, emblema irrevocable, nuestra Lengua, nuestra cultura, nuestros hombres de letras: filósofos, novelístas, poetas, artistas... gozarán de la más honda significación y sentido en América. Será sin duda, éste el cordaje de unión, el atisbo del alma hermana, aún alumbra. Así van a reconocerlo nuestros escritores de la generación del 98 (Valle-Inclán, Unamuno, Ortega y Gasset, Azorín..) y los intelectuales exila- 
dos durante la guerra de 1936: "Es nuestra guerra civil, la que al acusar durante su peripecia las confrontaciones, filias y fobias, en cada país iberoamericano, como si se tratara de su mismo interno conflicto, la que confiere incomparable significación humanística al regimen republicano, lo que será después el trastierro de mayor trancendencia y hondura. Ambas virtualidades no han generado todavía a mi entender, el haz de estudios sociológicos e históricos que merecen". (Manuel Andújar)

Mario Parajón, en un ensayo sobre Eugenio Florit y su poesía, dice: "Cuba no puede ni podrá nunca ser Cuba, como Hispanoamérica no puede ni podrá ser Hispanoamérica, si no aprende con lento apredinzaje a dar a España. Dar a España, no es españolizarse, no es renunciar ni al indio ni al negro... lo que si significa es poner pie en la realidad, admitir que las virtudes y las faltas de los padres son de los padres y no de los primos cuartos"

Pedro Henríquez Ureña, dominicano, afirmará que hay que ir hacia la utopía clásica. La de los griegos: "El pueblo griego da al mundo occidental la inquietud del perfeccionamiento constante, cuando descubre que el hombre puede individualmente ser mejor de lo que es y socialmente vivir mejor de como se vive, no descansa, hasta averiguar el secreto de toda mejora".

Finalmente coincidir con Edmundo O'Gorman, en cual afirma en " $\mathrm{La}$ intención de América": "El análisis de la historia del descubrimiento de América nos ha mostrado que estamos en presencia de un proceso interpretativo".

Verdaderamente, la interpretación dota de acierto o de desacierto, todas las cosas. Y en ella, el fluyente de ambos mundos, ha circulado, porque también ha sido un hecho que América latina lleva savia española, y España, no es España, sin hallar en su horizonte, a iberoamérica. En este rango, existe no sólo acercamiento, sino un sustrato básico, así como un ideal perfeccionable.

Actualmente, la única equiparación posible, la determina la técnica. Podría decirse que los imperios y su formación, como las ideologías políticas, han perdido rango, persuasión y conveniencia, y sólo un factor, el económico, y sólo una determinación de futuro, la tecnocracia, como la difusión y alcance de los medios técnicos, especialmente los de comunicación, que la distribuyen por todo ámbito, son los ideales, la aspiración en que se sumen los pueblos todos, la conquista auténtica y plausible, que conducirá, a una -hipotética todavía, aunque real— unidad. 
HISPANIDAD EN TORNO A LA CONQUISTA DE MEXICO

\section{B I B LIOGRAFIA}

SOLIS Y RIVADENEYRA, ANTONIO. La Conquista de México HERNÁN CORTÉS. Cartas de Relación.

HUGH THOMAS. La Conquista de México.

ANDÚJAR, MANUEL. Andalucla e Hispanoamérica, Crisol de Mestizajes.

TAMAYO, MANUEL. Historia Daimon, Vol. 5 Cap. "Los descubrimientos".

ALVAR, MANUEL. Lengua, Literatura y utopia. Revista "Blanco y Negro" de 16 de Abril de 1995. 